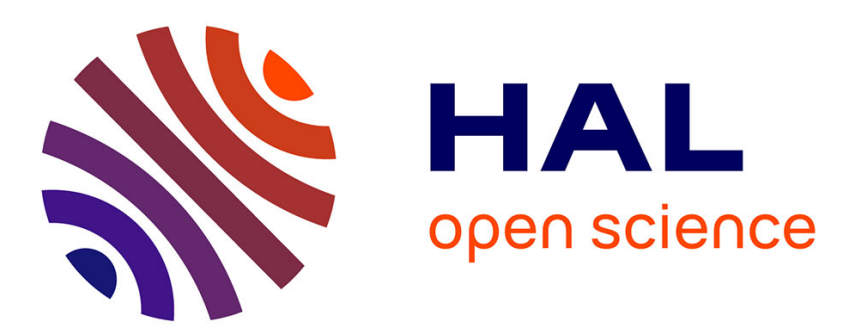

\title{
Metal-to-dielectric transition induced by annealing of oriented titanium thin films
}

Aurélien Besnard, Nicolas Martin, Luc Carpentier, Fabrice Sthal, Jean-Yves

Rauch

\section{- To cite this version:}

Aurélien Besnard, Nicolas Martin, Luc Carpentier, Fabrice Sthal, Jean-Yves Rauch. Metal-todielectric transition induced by annealing of oriented titanium thin films. functional Materials Letters, 2013, 6, pp.1250051. 10.1142/S1793604712500518 . hal-00875747

\section{HAL Id: hal-00875747 \\ https://hal.science/hal-00875747}

Submitted on 22 Oct 2013

HAL is a multi-disciplinary open access archive for the deposit and dissemination of scientific research documents, whether they are published or not. The documents may come from teaching and research institutions in France or abroad, or from public or private research centers.
L'archive ouverte pluridisciplinaire HAL, est destinée au dépôt et à la diffusion de documents scientifiques de niveau recherche, publiés ou non, émanant des établissements d'enseignement et de recherche français ou étrangers, des laboratoires publics ou privés. 


\section{Functional Materials Letters (FML) \\ Metal-to-dielectric transition induced by annealing of oriented titanium thin films --Manuscript Draft--}

\section{Manuscript Number:}

Full Title:

Article Type:

Section/Category:

Keywords:

Corresponding Author:
Metal-to-dielectric transition induced by annealing of oriented titanium thin films

Research Paper

Prof Jan Van Humbeeck

Sputtering; Thin films; Electrical properties; Metal; Dielectric.

nicolas MARTIN, PhD.

FEMTO-ST Institute

BESANCON, FRANCE

Corresponding Author Secondary Information:

Corresponding Author's Institution:

FEMTO-ST Institute

Corresponding Author's Secondary Institution:

First Author:

Aurelien BESNARD, Dr.

First Author Secondary Information:

Order of Authors:

Order of Authors Secondary Information:

Abstract:

Suggested Reviewers:

Author Comments:

\author{
Aurelien BESNARD, Dr. \\ nicolas MARTIN, PhD. \\ Fabrice STHAL, Pr. \\ LUc CARPENTIER, Dr. \\ Jean-Yves RAUCH, Dr.
}

Titanium thin films were deposited by dc magnetron sputtering. The GLancing Angle Deposition (GLAD) method was implemented to prepare two series of titanium films: perpendicular and oriented columnar structures. The first one was obtained with a conventional incidence angle of the sputtered particles $\left(=0^{\circ}\right)$, whereas the second one used a grazing incidence angle $=85^{\circ}$. Afterwards, films were annealed in air following 6 incremental cycles of temperatures ranging from 293 to $773 \mathrm{~K}$. Dc electrical conductivity was measured during the annealing treatment. Films deposited by conventional sputtering $\left(=0^{\circ}\right)$ kept a typical metallic-like behavior versus temperature $(300 \mathrm{~K}=2.0106 \mathrm{~S} \mathrm{~m}-1$ and TCR293K $=1.5210-3 \mathrm{~K}-1)$, whereas those sputtered with = $85^{\circ}$ showed a gradual transition from metallic to dielectric material. Such a transition was mainly attributed to the high porous structure, which favors the oxidation of titanium films to tend to the $\mathrm{TiO} 2$ compound.

Filipe VAZ, Dr.

Associate Professor, University of Minho

fvaz@fisica.uminho.pt

Specialist on thin films deposition and structural behaviors

Liping FENG, Dr.

Associate Professor, Northwestern Polytechnical University

flpmerry@yahoo.com

Specialist on dielectric properties of thin films produced by sputtering

Said AGOURAM, Dr.

Associate Professor, University of Valencia

said.agouram@uv.es

Specialist on sputtering processes

Dear Editor of Functional Materials Letters, 
Please find an original article entitled: "Metal-to-dielectric transition induced by annealing of oriented titanium thin films" written by Aurelien BESNARD, Nicolas MARTIN, Fabrice STHAL, Luc CARPENTIER and Jean-Yves RAUCH. Results presented in this letter are original and have never been published. They show a gradual transition from metal to dielectric of titanium thin films sputter deposited by the GLAD (glancing angle deposition) technique. Such transition is produced by an annealing treatment and simultaneously followed by dc electrical measurements. Conventional titanium thin films produced by classical sputtering do not exhibit this kind of transition and are compared to GLAD films. An analysis of the microstructure is discussed taking into account the high porous architecture produced by the GLAD method.

Sincerely,

Pr. Nicolas MARTIN 
Functional Materials Letters

Vol. x, No. x (2xxx) x-x

CCWorld Scientific Publishing Company

\title{
METAL-TO-DIELECTRIC TRANSITION INDUCED BY ANNEALING OF ORIENTED TITANIUM THIN FILMS
}

\author{
Aurélien BESNARD \\ LaBoMaP, Centre Arts et Métiers ParisTech de Cluny, Rue porte de Paris \\ 71250 CLUNY, France
}

Nicolas MARTIN*, Fabrice STHAL, Luc CARPENTIER, Jean-Yves RAUCH
Institut FEMTO-ST, UMR 6174 CNRS, Université de Franche-Comté, ENSMM, UTBM, 32, Avenue de l'Observatoire 25044 BESANCON Cedex, France
nicolas.martin@femto-st.fr

Received Day Month Year; Revised Day Month Year

\begin{abstract}
Titanium thin films were deposited by dc magnetron sputtering. The GLancing Angle Deposition (GLAD) method was implemented to prepare two series of titanium films: perpendicular and oriented columnar structures. The first one was obtained with a conventional incidence angle $\alpha$ of the sputtered particles $\left(\alpha=0^{\circ}\right)$, whereas the second one used a grazing incidence angle $\alpha=85^{\circ}$. Afterwards, films were annealed in air following 6 incremental cycles of temperatures ranging from 293 to $773 \mathrm{~K}$. Dc electrical conductivity was measured during the annealing treatment. Films deposited by conventional sputtering $\left(\alpha=0^{\circ}\right)$ kept a typical metallic-like behavior versus temperature $\left(\sigma_{300 \mathrm{~K}}=2.0 \times 10^{6} \mathrm{~S} \mathrm{~m}^{-1}\right.$ and $\left.\mathrm{TCR}_{293 \mathrm{~K}}=1.52 \times 10^{-3} \mathrm{~K}^{-1}\right)$, whereas those sputtered with $\alpha=85^{\circ}$ showed a gradual transition from metallic to dielectric material. Such a transition was mainly attributed to the high porous structure, which favors the oxidation of titanium films to tend to the $\mathrm{TiO}_{2}$ compound.
\end{abstract}

Keywords: Sputtering, thin films, electrical properties, metal, dielectric.

Metal-insulator transitions have been investigated for many years [1]. They often arise from variations of the chemical composition, temperature, stress, electric or magnetic field, etc. [2-4]. They correspond to a transformation between states with a dielectric (or semiconductor) and a metallic type of conductivity. Materials exhibiting these phenomena include binary compounds of transition metal oxides. As a result, these transitions have largely been explored for bulk materials like vanadium oxides [5], but few studies have been devoted to such transitions for other materials [6] and to the best of our knowledge, never for thin films exhibiting an oriented columnar structure.

In this work, we report on the effect of an annealing treatment on the micro-structural properties, optical behaviors and dc electrical conductivity of titanium films sputter deposited. Two series of samples were prepared. The first one was conventionally prepared with a normal incidence angle $\alpha$ of the sputtered particles $\left(\alpha=0^{\circ}\right)$. For the second series, the GLancing Angle Deposition (GLAD) was implemented to produce an oriented columnar structure. An incidence angle $\alpha=85^{\circ}$ was used to deposit an oriented structure. Both series were heated in air following 6 cycles from 293 to $773 \mathrm{~K}$. Titanium films obtained at normal incidence $\left(\alpha=0^{\circ}\right)$ kept a metallic-like behavior, whereas those deposited by GLAD $\left(\alpha=85^{\circ}\right)$ exhibited a gradual metal-to-dielectric transition. Such a transition comes from the oxidation of the GLAD titanium films due to a high porous structure of the oriented columnar architecture.

Magnetron sputtering was implemented to deposit 300 $\mathrm{nm}$ thick titanium thin films. A pure titanium disk (99.8 at. $\%$ and $50 \mathrm{~mm}$ diameter) was dc sputtered using a constant current density of $100 \mathrm{~A} \mathrm{~m}^{-2}$. Before introducing argon gas at a sputtering pressure of $10^{-1} \mathrm{~Pa}$ (pumping speed of $10 \mathrm{~L} \mathrm{~s}^{-}$ ${ }^{1}$ ), the chamber was pumped down to $10^{-5} \mathrm{~Pa}$. Films were deposited on (100) silicon and glass substrates after cleaning in acetone and alcohol. A home made GLAD substrateholder allowed the preparation of oriented columnar structure by changing the incidence angle $\alpha$ of the particles flux from $\alpha=0$ to $90^{\circ}$ and/or rotating the substrate holder at

*Corresponding author 
various rotating speeds. In this work, two types of films were prepared without using a rotation of the substrate holder (inclined and fixed substrate only). The first series was deposited using a classical incidence angle $\alpha$ of the particles flux (i.e. $\alpha=0^{\circ}$ ). The second series implemented an incidence angle $\alpha=85^{\circ}$. Optical transmittance versus wavelength was measured in the visible range for films deposited on glass substrates with a PerkinElmer Lambda 950 spectrophotometer. Cross-section and surface of the films were observed by Scanning Electron Microscopy (SEM) with a JEOL JSM-6400F. Dc electrical conductivity of the films deposited on glass substrates was measured in the van der Pauw geometry. The home made system allows the conductivity measurements as well as the annealing treatment in air for temperatures ranging from 293 to $773 \mathrm{~K}$. Six cycles were systematically applied for all films. The first cycle started from room temperature up to $523 \mathrm{~K}$ at $5 \mathrm{~K}$ $\mathrm{min}^{-1}$ followed by a return to room temperature at $5 \mathrm{~K} \mathrm{~min}^{-1}$. The second cycle was similar up to $573 \mathrm{~K}$ (increment of 50 $\mathrm{K})$. The third cycle was up to $623 \mathrm{~K}$ and so on until the last cycle $\left(6^{\text {th }}\right)$, which reached $773 \mathrm{~K}$.

A columnar microstructure is produced for any incidence angle of the sputtered titanium atoms (Fig. 1). Columns are poorly defined for films deposited with a conventional incidence angle $\left(\alpha=0^{\circ}\right.$ in Fig. 1c). Films rather exhibit a densely packed structure. Since titanium films have been sputtered with an argon pressure of $10^{-1} \mathrm{~Pa}$ and with no external heating of the substrate during deposition, the microstructure corresponds to the $\mathrm{T}$ zone of the Thornton's structural zone model [7]. More defined columns are observed for titanium films obtained with an incidence angle $\alpha=85^{\circ}$. An inclined columnar structure is clearly achieved with a column angle $\beta=40^{\circ}$ (Fig. 1g). As commonly observed with the GLAD technique, such column angle $\beta$ is below the incidence angle $\alpha$ mainly due to shadowing effect at the atomic scale [8]. In addition, it is below the angle predicted by empirical rules proposed by Nieuwenhuizen and Haanstraa (tangent's rule) [9] or from geometric relationships suggested by Tait et al. [10] because of the sputtered atoms - argon collisions occurring between the target and the substrate. Smooth surface is observed for conventional sputtering (Fig. 1a) whereas films prepared with an incidence angle $\alpha=85^{\circ}$ exhibit a more corrugated aspect (Fig. 1e). Tops of the columns are clearly distinguished and the voids surrounding the columns are larger. After annealing cycles (6 incremental cycles up to $773 \mathrm{~K})$, the weakly defined columnar structure is kept for the film deposited at normal incidence $\alpha=0^{\circ}$ (Fig. 1d), but more defects can be observed on the surface (bright dots in Fig. 1b). One can suggest that a thin oxide layer (few nanometers thick) is developed on the top of the columns, especially on defects. For annealed films deposited with an incidence angle $\alpha=85^{\circ}$, it is worth of noting that the columnar structure is not destroyed (Fig. 1h).

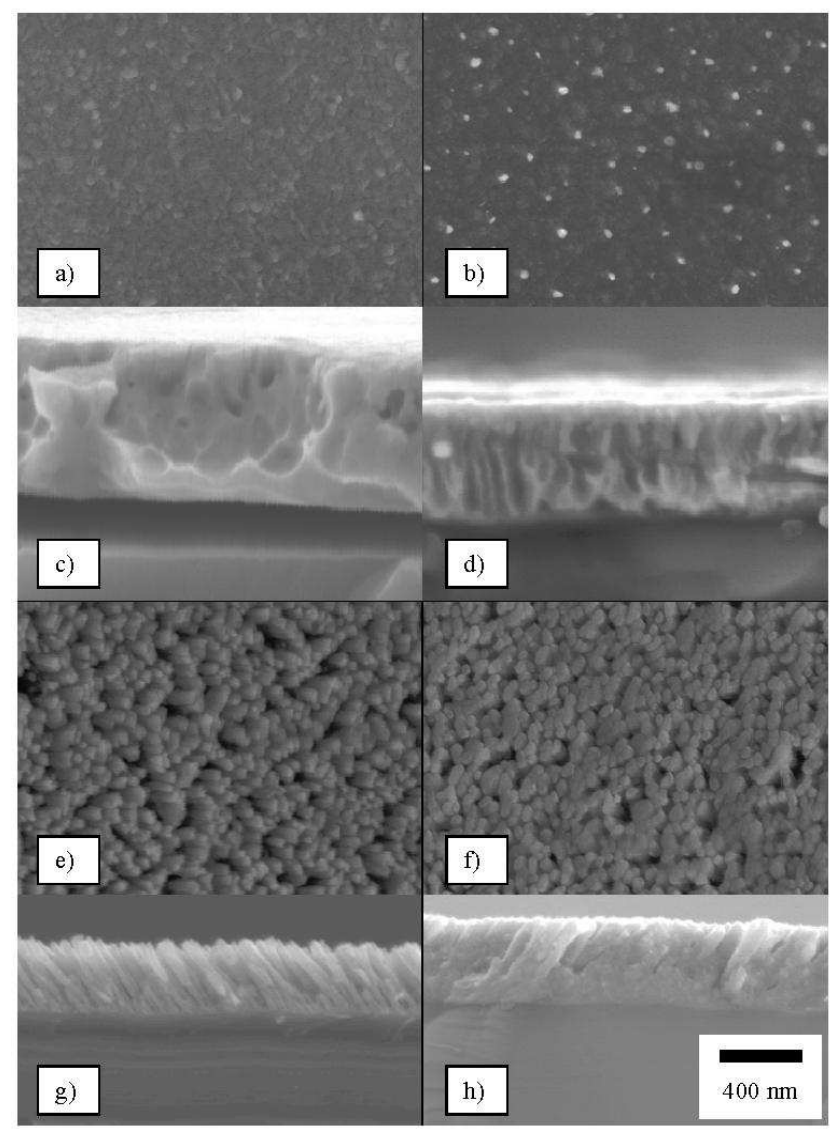

Fig. 1. SEM observations of cross-sections and surfaces of titanium films deposited: a) to d) with a normal incidence angle of the sputtered particles (first series; $\alpha=0^{\circ}$ ); e) to h) by GLAD (second series; $\alpha=85^{\circ}$ ). The columnar microstructure is kept in spite of the annealing treatment as shown in b), d), f) and h) photographs.

The surface morphology previously observed for nontreated titanium films is very similar (Fig. 1e). Regular columns (about $50 \mathrm{~nm}$ diameter) separated by voids are clearly observed, which reveals a porous structure (Fig. 1f).

For all annealing cycles, titanium films conventionally deposited $\left(\alpha=0^{\circ}\right)$ exhibit conductivity versus temperature typical of a metallic-like behavior since electrical conductivity is $\sigma_{293 \mathrm{~K}}=1.22 \times 10^{6} \mathrm{~S} \mathrm{~m}^{-1}$ at $293 \mathrm{~K}$ and linearly drops down to $\sigma_{773 \mathrm{~K}}=7.39 \times 10^{5} \mathrm{~S} \mathrm{~m}^{-1}$ at $773 \mathrm{~K}$ (Fig. 2).

A positive temperature coefficient of resistance $\mathrm{TCR}=$ $1.52 \times 10^{-3} \mathrm{~K}^{-1}$ is obtained. Conductivity as well as TCR are lower than the bulk value $\left(\sigma_{293 \mathrm{~K}}=2.56 \times 10^{6} \mathrm{~S} \mathrm{~m}^{-1}\right.$ at $293 \mathrm{~K}$ and TCR $=5.50 \times 10^{-3} \mathrm{~K}^{-1}$ for bulk titanium). It is commonly observed for metallic thin films and mainly attributed to the scattering of electrons at the grain boundaries [11]. 
For titanium films prepared with an incidence angle $\alpha=$ $85^{\circ}$, conductivity is strongly modified by the annealing cycles. Before increasing the temperature, conductivity at room temperature is $\sigma_{293 \mathrm{~K}}=1.56 \times 10^{5} \mathrm{~S} \mathrm{~m}^{-1}$. This value is one order of magnitude lower than those previously measured for the titanium film deposited without GLAD $\left(\sigma_{293 \mathrm{~K}}=1.22 \times 10^{6} \mathrm{~S} \mathrm{~m}^{-1}\right.$ for $\left.\alpha=0^{\circ}\right)[12]$.

\section{Temperature $\mathrm{T}(\mathrm{K})$}

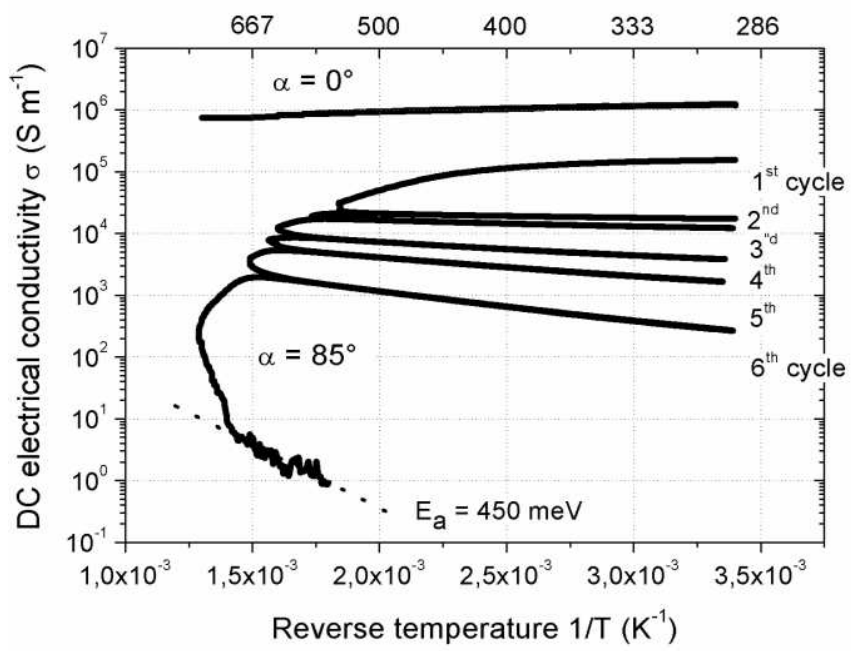

Fig. 2. Dc electrical conductivity as a function of the reverse temperature of titanium films sputter deposited. First series (normal incidence of the sputtered particles, i.e. $\alpha=0^{\circ}$ ) keeps a metallic-like behaviour. Second series (GLAD films at an incidence angle $\alpha=85^{\circ}$ ) exhibits a gradual metalto-dielectric transition.

As the temperature rises up to $333 \mathrm{~K}$ and as expected for metallic compounds, conductivity is linearly reduced. A further increase of temperature up to $523 \mathrm{~K}$ leads to a non linear evolution of the conductivity versus temperature and drops down to $\sigma_{523 \mathrm{~K}}=2.31 \times 10^{4} \mathrm{~S} \mathrm{~m}^{-1}$. It is mainly attributed to the oxidation beginning of the titanium film. The return to the room temperature shows a decrease of the electrical conductivity, which is characteristic of either a semiconducting-like behavior observed for oxygen-deficient $\mathrm{TiO}_{2-\delta}$ with low activation energy [13], or a metallic-like behavior of oxygen-rich $\mathrm{TiO}_{1+\varepsilon}$ with negative TCRs [14]. The additional annealing treatments $\left(2^{\text {nd }}\right.$ to $5^{\text {th }}$ cycles) emphasize the oxidation phenomenon of the films. At the beginning of the $2^{\text {nd }}$ cycle, conductivity is $\sigma_{293 \mathrm{~K}}=1.73 \times 10^{4}$ $\mathrm{S} \mathrm{m}^{-1}$ and gradually falls down to $\sigma_{293 \mathrm{~K}}=2.67 \times 10^{2} \mathrm{~S} \mathrm{~m}^{-1}$ before starting the $6^{\text {th }}$ cycle. In addition, the negative slope of $\log (\sigma)$ versus the reverse temperature becomes more significant. One can suggest that the film is more and more oxidized. The last annealing cycle (from 293 to $773 \mathrm{~K}$ ) leads to the most important decrease of the conductivity. At $773 \mathrm{~K}, \sigma_{773 \mathrm{~K}}$ is $2.14 \times 10^{2} \mathrm{~S} \mathrm{~m}^{-1}$. Reducing the temperature, conductivity looses again 3 orders of magnitude and reaches $\sigma_{556 \mathrm{~K}}=8.21 \times 10^{-1} \mathrm{~S} \mathrm{~m}^{-1}$ at $556 \mathrm{~K}$. A further reduction of temperature does not allow conductivity measurements with our van der Pauw system. However, the negative slope obtained between 556 and $717 \mathrm{~K}$ suggests a linear behavior in the Arrhenius plot. The activation energy $E_{a}$ calculated from the $\log (\sigma)$ versus the reverse temperature curve gives rise to $E_{a}=430 \mathrm{meV}$. It remains below typical values observed for stoichiometric titanium dioxide thin films $\left(E_{a}\right.$ is close to $650 \mathrm{meV}$ [15]), but it is in agreement with previous studies focused on oxygen-deficient $\mathrm{TiO}_{2}$ compounds exhibiting dielectric properties [16-18].

Optical transmittance versus wavelength supports the dielectric behaviors achieved by titanium films deposited with an incidence angle $\alpha=85^{\circ}$ after the annealing treatment (Fig. 3). Films are transparent with an optical transmittance close $60 \%$ at $589 \mathrm{~nm}$. In addition, some interference fringes are clearly viewed. Similarly, $\mathrm{TiO}_{2}$ thin films $200 \mathrm{~nm}$ thick deposited by dc reactive magnetron sputtering (argon + oxygen atmosphere) using a normal incidence of particles $\left(\alpha=0^{\circ}\right)$ and an inclined orientation $(\alpha$ $=85^{\circ}$ ) are shown

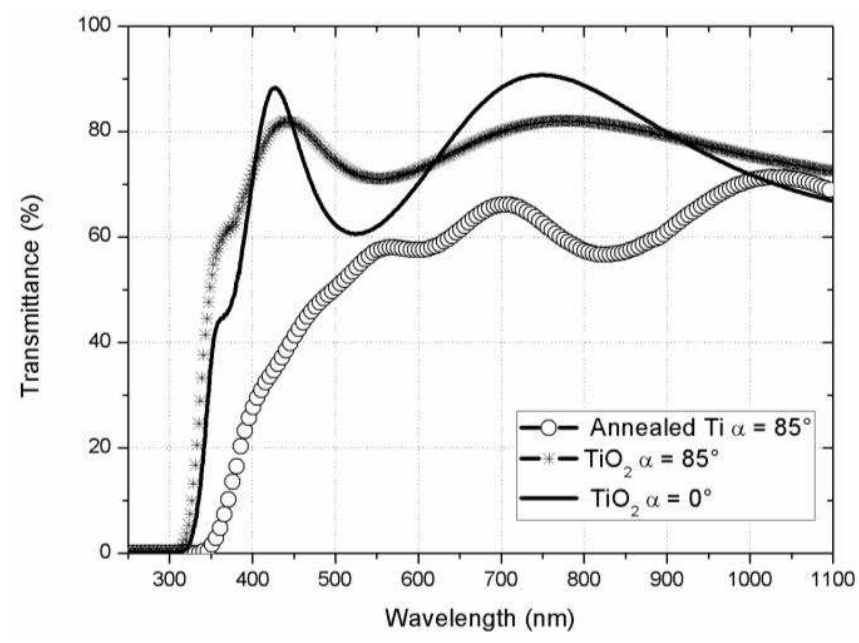

Fig. 3. Optical transmittance spectra versus wavelength in the visible region of GLAD titanium thin films deposited on glass substrates with an incidence angle $\alpha=85^{\circ}$ and after the annealing procedure in air up to 773 $\mathrm{K}$. Typical interference fringes are measured and can be compared to those observed for titanium dioxide thin films (thickness $200 \mathrm{~nm}$ ) produced by classical dc reactive sputtering ( $\mathrm{Ar}+\mathrm{O}_{2}$ atmosphere) for an incidence angle $\alpha=0$ and $85^{\circ}$.

It is interesting to note that the amplitude of the fringes and thus, refractive indices are strongly influenced by the incidence angle $\alpha$. Refractive index at $589 \mathrm{~nm}$ " $\mathrm{n}_{589}$ " was calculated from transmittance spectra by the Swanepoel's method [19]. For normal incidence $\left(\alpha=0^{\circ}\right), \mathrm{n}_{589}=2.48$ whereas it is lower than 1.93 for $\alpha=85^{\circ}$ mainly due to a high porous structure produced for high incidence angles 
[20]. For annealed films, $\mathrm{n}_{589}=1.84$, which is lower than the value of $\mathrm{TiO}_{2}$ film prepared with $\alpha=85^{\circ}$. As a result, optical transmittance in the visible region support the dielectric characteristics of annealed titanium films deposited by GLAD with an incidence angle $\alpha=85^{\circ}$.

In summary, titanium thin films were sputter deposited using the GLAD method. A conventional incidence angle $\alpha$ of the sputtered particles $\left(\alpha=0^{\circ}\right)$ was first used, whereas other films were prepared with a grazing incidence angle $\alpha$ $=85^{\circ}$. Films were annealed in air according to 6 cycles of temperatures ranging from 293 to $773 \mathrm{~K}$. Films deposited at normal incidence $\left(\alpha=0^{\circ}\right)$ kept a metallic-like behavior versus temperature in spite of heating. On the other hand, films obtained with an incidence angle $\alpha=85^{\circ}$ exhibited a gradual change of their electrical conductivity. Before annealing, metallic-like properties were observed with a room temperature conductivity higher than $\sigma=1.22 \times 10^{6} \mathrm{~S}$ $\mathrm{m}^{-1}$. After 6 annealing cycles, conductivity was below $1 \mathrm{~S}$ $\mathrm{m}^{-1}$ and became too much resistive to be measured by the four probe method. Similarly, optical transmittance as well as refractive index in the visible region exhibited typical optical characteristics close to that of $\mathrm{TiO}_{2}$ insulating materials. Such a gradual metal-to-dielectric transition solely observed for GLAD titanium films, was mainly related to the oxidation phenomenon of the high porous structure especially favored for grazing incidence angles.

\section{Acknowledgement}

The authors thank the Région of Franche-Comté and the city of Besançon for financial supports.

\section{References}

1. N. F. Mott, Rev Mod Phys 40, 677 (1968).

2. M. Imada et al., Rev Mod Phys 70, 1039 (1998).

3. I. Balslev and J. E. Furneaux, Solid State Commun 32, 609 (1979).

4. C. Zhou et al., Appl Phys Lett 70, 598 (1997).

5. J. Fujioka et al., Phys Rev B 72, 024460 (2005).

6. J. Guillot et al., Acta Mater 51, 3067 (2006).

7. J. Thornton, J Vac Sci Technol 11, 666 (1974).

8. K. Robbie et al., J Vac Sci Technol B16(3), 1115 (1998).

9. J. M. Nieuwenhuizen and H. B. Haanstra, Philips Tech Rev 27, 87 (1966).

10. R. N. Tait et al., Thin Solid Films 226, 196 (1993).

11. G. Reiss et al., Phys Rev Lett 56, 2100 (1986).

12. A. Besnard et al., J Phys D: Appl Phys 44, 215301 (2011).

13. N. Martin et al., Thin Solid Films 377-378, 550 (2000).

14. O. Banakh et al., Surf Coat Technol 151-152, 272 (2002).

15. K. Prasad et al., (1997) Jpn J Appl Phys 36, 5696 (2002).

16. S. G. Springer et al., Surf Coat Technol 151-152, 51 (2002).

17. N. Martin et al., Appl Phys Lett 93, 064102 (2008).

18. N. Martin et al., Int J Mater Prod Technol 39, 159 (2010).
19. R. Swanepoel, J Phys E: Sci Intrum 16, 1214 (1983).

20. K. Robbie and M. J. Brett, J Vac Sci Technol A15(3), 1460 (1997). 
Figure 1

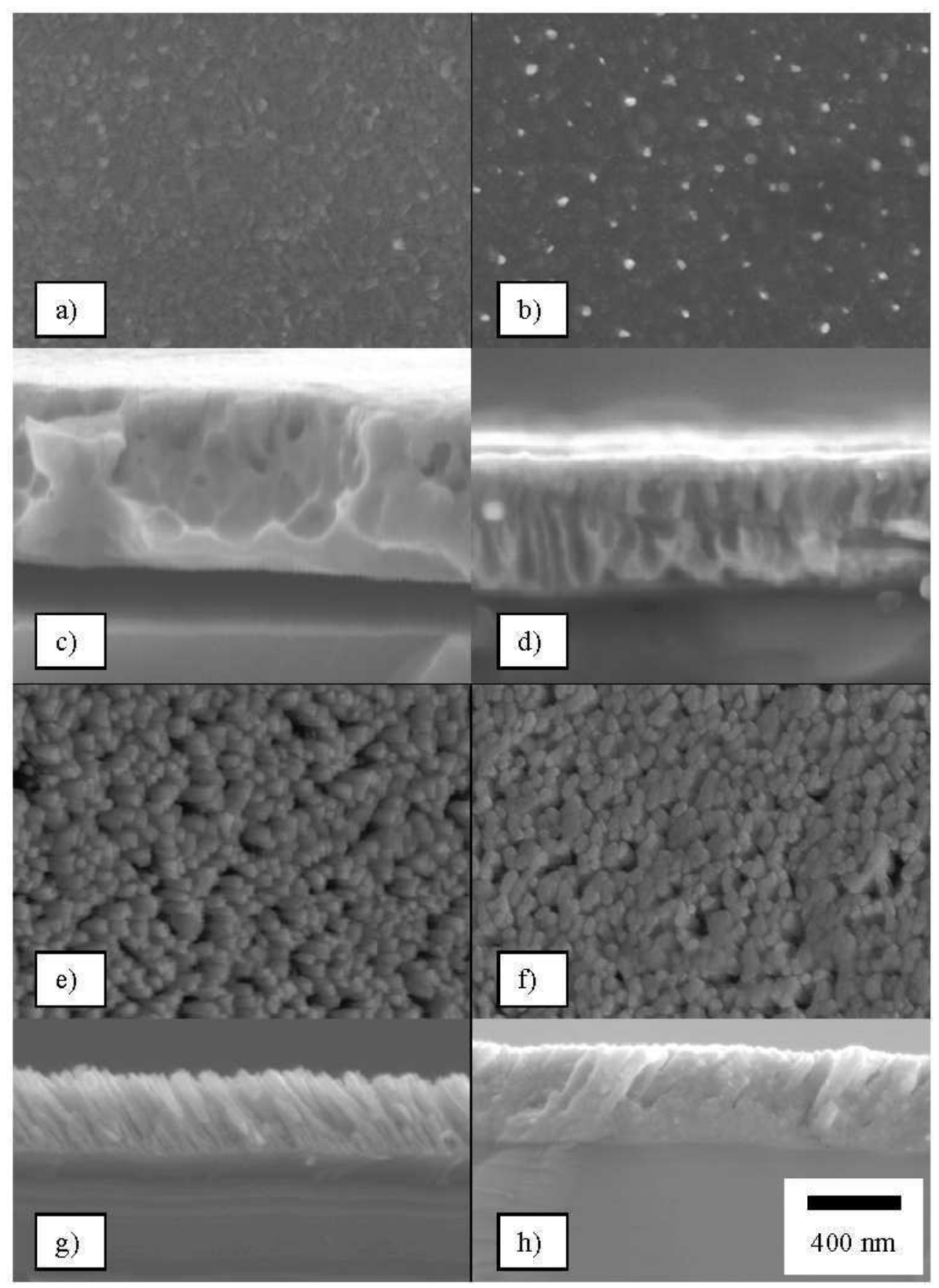


Temperature $\mathrm{T}(\mathrm{K})$

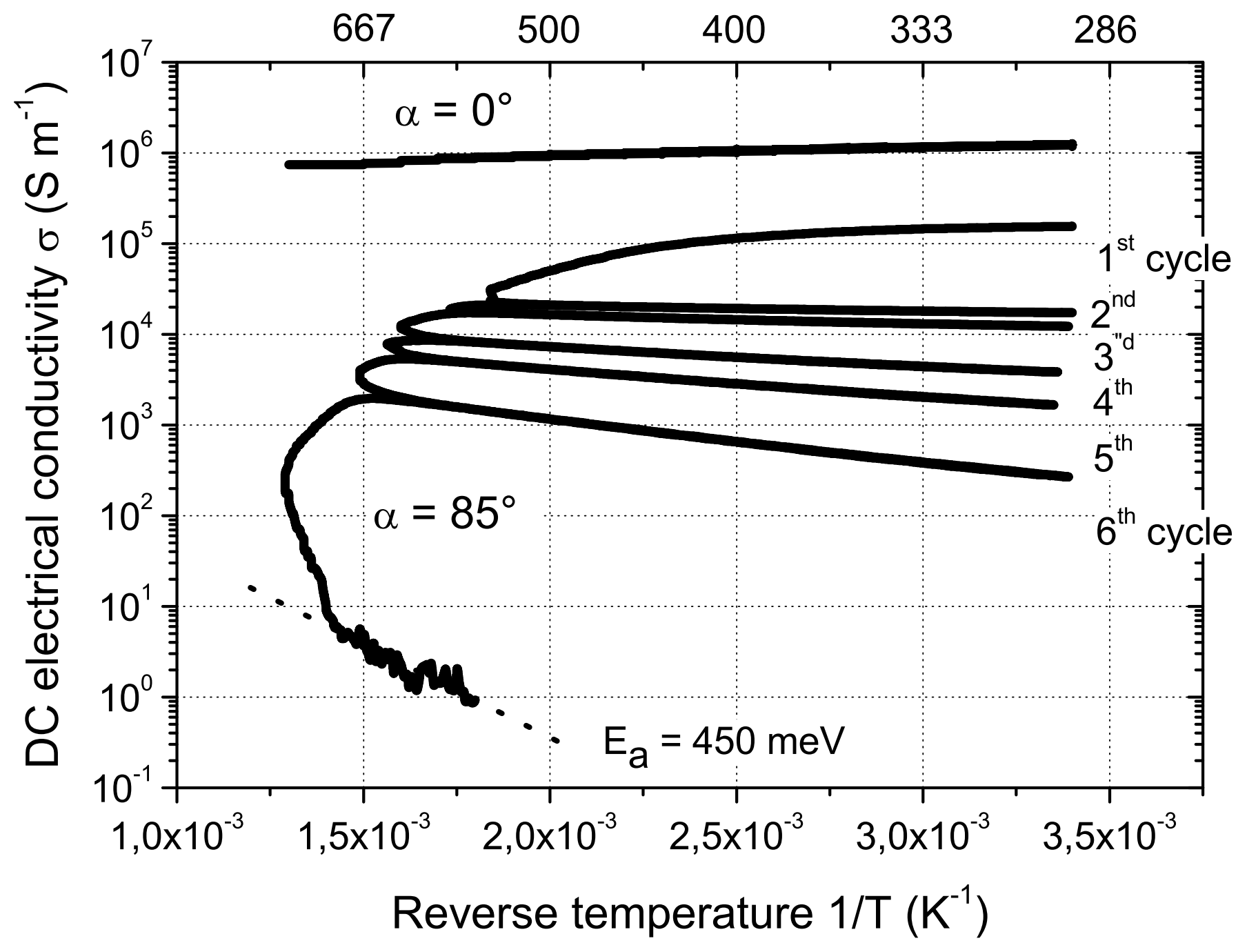


Figure 3

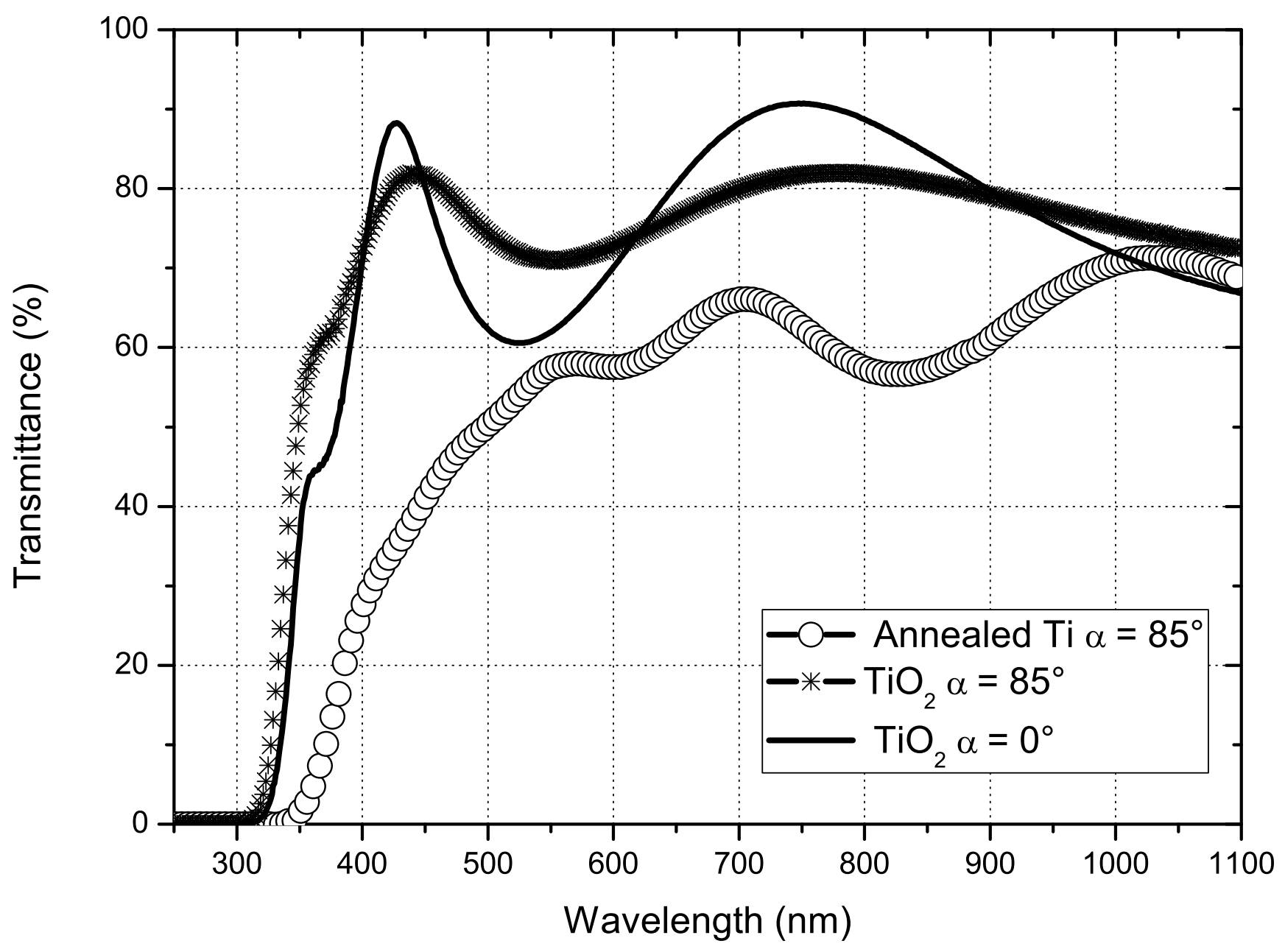

